\title{
Innovative Geospatial Solutions for Land Tenure Mapping
}

Koeva, M. ${ }^{1}$, Stöcker, C. ${ }^{1}$, Crommelinck, S. ${ }^{1}$, Chipofya, M. ${ }^{1}$, Kundert, K. ${ }^{2}$, Schwering, A. ${ }^{3}$, Sahib, J. ${ }^{3}$, Zein, T. ${ }^{4}$, Timm, C. ${ }^{4}$, Humayun, M. I. ${ }^{4}$, Crompvoets, J. $^{5}$, Tan, E. ${ }^{5}$, Casiano, C. $^{5}$, Nkerabigwi, P. ${ }^{6}$

1. University of Twente, Faculty of Geo-Information Science and Earth Observation (ITC), 7514 AE Enschede, The Netherlands

2. ESRI Rwanda, 18 KG 5 Ave, Kigali, Rwanda,

3. Institute for Geoinformatics, Westfälische Wilhelms-Universität Münster, Heisenbergstrasse 2, 48149 Münster, Germany

4. Hansa Luftbild, Nevinghoff 20, 48147 Münster, Germany

5. Public Governance Institute, 3000 KU Leuven, Belgium

6 INES, Ruhengeri, P.O. Box: 155 Ruhengeri, Rwanda

Correspondence: Mila Koeva, Email: $\underline{\text { m.n.koeva@utwente.nl }}$

\begin{abstract}
:
There are millions of unrecorded land rights in sub-Saharan Africa, which are still not mapped. Therefore, there is a clear demand for innovative solutions for land tenure recording, as also written in the target 1.4 of UN Sustainable Development Goals (SDGs). In response to this need, the consortia of "its4land" European Commission Horizon 2020 project developed the "its4land toolbox" based on the continuum of land rights and fit-for-purpose approach. The advanced technological solutions of the toolbox include smart sketch maps, Unmanned Aerial Vehicles (UAVs), interactive boundary delineator, as well as sharing and publishing land information via geocloud services. The solutions are based on specific needs, market opportunities, and readiness of end-users. Moreover, aiming in scaling up broader governance implications are examined. During the project lifetime, the main technical tasks included tool development, prototyping, and demonstration of the tools to local, regional, national, and international users and stakeholders. Furthermore, equal emphasis was placed on needs assessment, governance, capacity, and busines s modeling. The current paper presents the unique its4land land administration toolbox in which the key exploitable results of the project are integrated in a joint used case in Rwanda.
\end{abstract}

Keywords: Fit-for-Purpose; Land Tenure; UAV; Boundary Delineation; Land

\section{Introduction}

It was estimated that around two-thirds of the global population has access to a formal cadastral system (Enemark, McLaren, Lemmen, Antonio, \& Gitau, 2016). There are millions of unrecorded land rights in sub-Saharan Africa, which are still not mapped. (M. N. Koeva et al., 2017). The classical approaches using total stations, theodolites, or Global Navigation Satellite Systems (GNSS), even being very accurate, turned to be too time-consuming and expensive. As a result, many local cadaster systems are incomplete and provoke land disputes. There is a clear demand for innovative solutions for land tenure recording, as also written in the target 1.4 of UN Sustainable Development Goals (SDGs). Recently, new approaches have been explored in support 
of efficient land administration. The so-called fit-for-purpose (FFP) concept has been developed and advertised, which aims in developing, adapting, and applying solutions that match the specific country contexts (Enemark et al., 2016).

In support of developing new FFP tools, the consortia of the "its4land" project developed innovative geospatial solutions combined in the so-called "its4land toolbox" (Mila Koeva et al., 2020). It consists of software tools and consultancy services that respond to the continuum of land rights and FFP approach (M. N. Koeva et al., 2017; M. N. Koeva, Crommelinck, Stöcker, \& Crompvoets, 2018). The innovative technological solutions include 1) a unique ontological analysis approach using smart sketch maps, 2) unmanned aerial vehicles (UAV) for mapping, and 3) Automatic Boundary Extraction (ABE), based on the acquired UAV images and 4) publish and share $(\mathrm{PaS})$ platform providing geocloud services.

The sketch maps are hand-drawn either on a blank paper, map, or image. They are not based on measurements but on people's observations, therefore thy are not georeferenced (Chipofya, Jan, Schultz, \& Schwering, 2017). The applicability of UAVs for mp creation and updating was also explored in a different context (M. Koeva, Muneza, Gevaert, Gerke, \& Nex, 2018). An imagebased approach has been used in many countries for manual delineation (IAAO, 2015). However, since this is quite a time-consuming procedure, innovative and scalable solutions using semiautomatic or interactive functionalities were explored (S. Crommelinck, Bennett, Gerke, Yang, \& Vosselman, 2017; S. Crommelinck, Höfle, Koeva, Yang, \& Vosselman, 2018; S. C. Crommelinck et al., 2017; Xia, Koeva, \& Persello, 2019; Xia, Persello, \& Koeva, 2019).

The main aim of the its4land was to develop solutions taking into account the specific needs, market opportunities, and readiness of end-users. Moreover, we aim to examine broader governance insinuations related to scaling the suggested solutions. The main technical tasks included tool development, prototyping, and demonstration for local, regional, and international stakeholders.

In this paper, we aim to show the integrated key exploitable results (KER) of the its4land for a joint-use case in Musanze, Rwanda. The combination of quantitative and qualitative results, taking into account both social and technical aspects, makes this paper a significant contribution both for academics and practitioners. The multidisciplinary nature of the current work, using different integrated approaches, is innovative to the land administration domain.

\section{Background}

The its4land project is a "Research and Innovation Action" of the European Commission's Horizon 2020 Industrial Leadership program. The consortium is multi-sectoral, multi-national, and multidisciplinary. It consists of SMEs and researchers from (KUL - KU Leuven) Belgium, (BDU 
- Bahir Dar University) Ethiopia, (WWU - University of Muenster; Hansa Luftbild) Germany, (Technical University of Kenya) Kenya, (University of Twente) the Netherlands), and (INES Ruhengeri; ESRI Rwanda) Rwanda. The transdisciplinary work covers the development of innovative smart geospatial solutions and supportive models for governance, capacity building, and business capitalization.

\subsection{Rwanda}

In the past 20 years, Rwanda has initiated institutional and legal reforms. As a result, the nationwide land registration program called "Land Tenure Regularization" (LTR) based on lowcost, fit-for-purpose, community-based solutions was created. Between 2009 and 2013 in Rwanda were registered more than 10 million land parcels. The formalization of land in Rwanda was based on aerial images for the community-driven demarcation process, digitization of all land data collected, and further centralization in a national land register and cadastre (Thierry Ngoga, 2017). However, the challenge of keeping the up-to-date system remains. However, there are economic and administrative factors that affect its realization due to current mechanisms. During fieldwork, the its4land team found out that basic topographic information such as buildings and plots are missing in the database of Rwanda. Therefore, selecting fit-for-purpose geospatial technology to speed up updating the system in an affordable, accurate, and easy way is definitely of interest. Based on the observations mentioned above, Musanze was selected as a case study location for the joint use case.

\section{3. its 4land KER and methods for their de velopment}

All the KERs resulting from the its4land project are bundled in the its4land toolbox (Table1), a box that offers consultancy services and software tools which can be ordered separately or jointly by the interested entities or organizations. They all have been developed in a different way therefore, a brief explanation of the used methods is explained in the following subsections. 
Table 1: KER of its4land project.

\begin{tabular}{|c|c|c|}
\hline KER Type & KER Name & KER Brief Description \\
\hline Consultancy services & Needs Assessment & Consultancy services assessing the local needs \\
\hline Software tool & $\begin{array}{l}\text { SmartSkeMa Data } \\
\text { Collection Tool }\end{array}$ & $\begin{array}{l}\text { SmartSkeMa is a tool based on hand-drawn sketch } \\
\text { maps recording people to land relationships }\end{array}$ \\
\hline $\begin{array}{l}\text { Consultancy } \\
\text { and }\end{array}$ & $\begin{array}{l}\text { UAV-based Data } \\
\text { Acquisition }\end{array}$ & $\begin{array}{l}\text { Consultancy services for data acquisition with } \\
\text { UAVs. OrtoGenerator tool imbedded in Publish } \\
\text { and Share platform }\end{array}$ \\
\hline Software tool & $\begin{array}{l}\text { Boundaries } \\
\text { Delineator }\end{array}$ & $\begin{array}{l}\text { A tool (plugin in QGIS) that helps for interactive } \\
\text { image-based cadastral mapping based on visible } \\
\text { boundaries on a high-resolution imagery }\end{array}$ \\
\hline Software tool & Publish and Share & Platform in which all its4land tools are integrated \\
\hline Consultancy services & $\begin{array}{l}\text { Governance and } \\
\text { Capacity } \\
\text { development }\end{array}$ & $\begin{array}{l}\text { Consultancy services to assess and overcome } \\
\text { governance and capacity development challenges } \\
\text { for implementing the tools }\end{array}$ \\
\hline
\end{tabular}

\subsection{Consultancy services for needs as sessment}

The user needs assessment was conducted by the partners from KU Leuven using a Nominal Group Technique (NGT), which is a behavioral-science-based method. It was developed to support the identification of problems and solutions amongst groups of stakeholders by facilitating equal participation (Delbecq \& Van de Ven, 1971; Gallagher, Hares, Spencer, Bradshaw, \& Webb, 1993). During the sessions, several questions were asked, and after two hours, all answers were discussed and ranked based on voting. A more detailed explanation is provided in (Ho, Pattyn, Broucker, \& Crompvoets, 2018). The needs assessment activities were done before the fieldworks and workshops related to tool development. Data was collected from government representatives, county level officials, surveyors, experts in land registration, and planning. They were selected by local land administration experts using purposive and snowball sampling. Thirty-eight organizations were contacted; of these, 22 participated (58\% response rate). Three workshops were held at local and national levels where one question led the discussion: "What land tenure and land-related information are still needed for sustainable urbanization?".

\subsection{SmartSkeMa}

Smart Sketch Maps (SmartSkeMa) is a tool developed by the University of Munster (WWU) to support the documentation of land tenure information from the perspective of the local people. The work consisted of (i) development of a domain model of concepts used to describe land tenure from a local perspective; (ii) development of spatial models for representing sketch maps; and (iii) development of methods for recognition of sketch maps (Murcia et al. 2018) and for embedding the sketch maps within existing spatial data sets. SmartSkeMa supports land tenure in two ways (Chipofya et al., 2017). First, it documents land-related concepts in a structured domain model as described by the local owners (Karamesouti et al., 2018). Second, it supports the mapping processes by digitizing, annotating, and georeferencing hand-drawn objects in a sketch map (Schwering et al., 2014). In Figure 1, the alignment of sketched maps to produced orthophoto is illustrated.SmartSkeMa targets NGOs, private organizations, research institutions, and 
government agencies. The initial setup of the tools and the follow-up support is offered as a service.

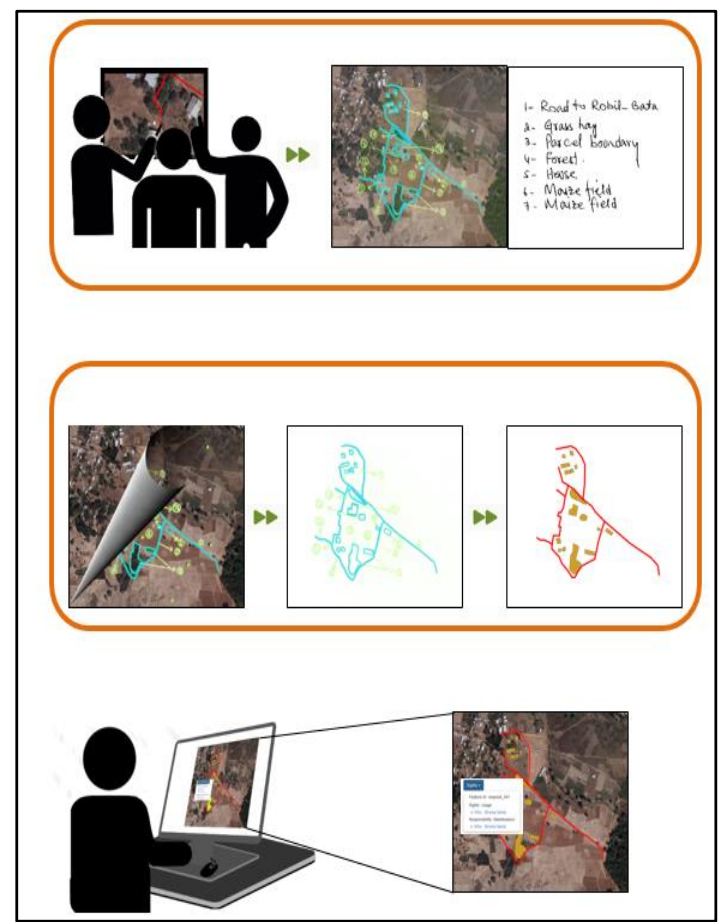

Figure 1: Workflow for aligning sketch maps to the orthophoto.

\subsection{Consultancy services and UAV OrtoGene rator tool}

The consultancy services include guidelines and workflows for data acquisition using UAVs for land administration. The generic workflow is depicted in Figure 2

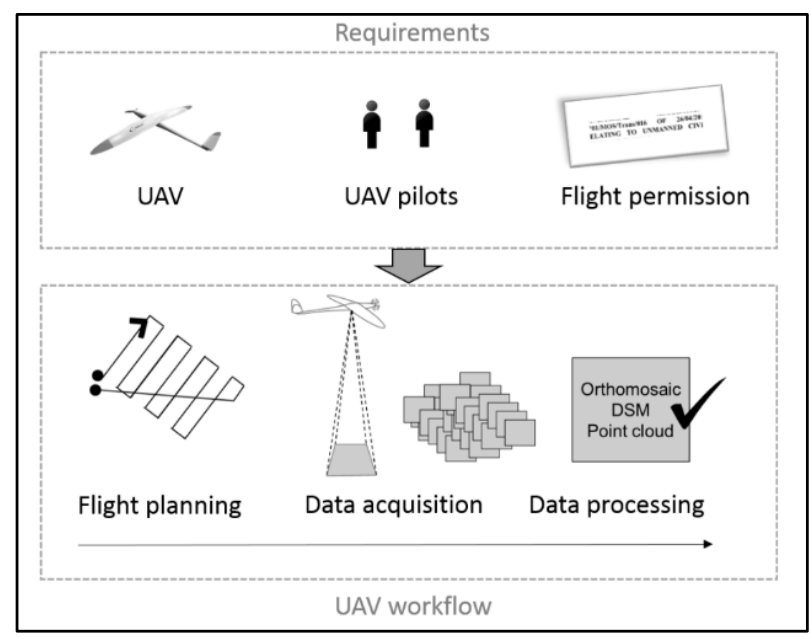

Figure 2: Generic workflow for UAV-based data acquisition.

As a starting point, careful investigation of the policies and legal requirements regarding the implementation of UAV data acquisition should be done. The outcome of this investigation, taking into account the country context, is necessary in order to design efficient workflows that are able to meet the user's expectations for the concrete applications. In this context, the workflow encompasses the entire operational UAV procedure, including UAV itself, UAV pilots, application for flight permission, flight planning and preparation, data acquisition, processing, and quality assessment. 
The consultancy UAV services target surveyors and experts in the land administration sector. However, NGOs, local communities, or government organizations can also use the workflow and request consultancy if they want to use UAVs for different applications.

In addition to the consultancy services, its4land developed a tool called "OthoGenerator" which is integrated into the PaS platform. It can be used as a tool for creating orthophotos from UAV images. It is based on OpenDrone Map, which is an open-source image processing application. The tool uses state of the art photogrammetry and structure from motion to generate customized products such as a 3D point cloud, a digital surface model (DSM), and an orthophoto. In the OrthoGenerator, the user needs to import the raw UAV images and to specify the resolution, image overlap, context of the scene, and the mode of georeferencing.

\subsection{Semi-automatic deline ator of visible cadastral boundaries}

The software tool, developed by the University of Twente (ITC), supports the delineation of visible boundaries by semi-automatic information extraction from RGB aerial or satellite imagery by coupling this information with the subsequent delineation procedure. The tool focuses on improving current indirect surveying approaches in terms of cost, time, and accuracy. The methods used for the development of the tool are explained in detail in (S. Crommelinck, Koeva, Yang, \& Vosselman, 2019) and visualized in Figure 3. It consists of: (a) image segmentation, (b) boundary classification, and (c) interactive delineation. The source code is publicly available (Crommelinck.S, n.d.).
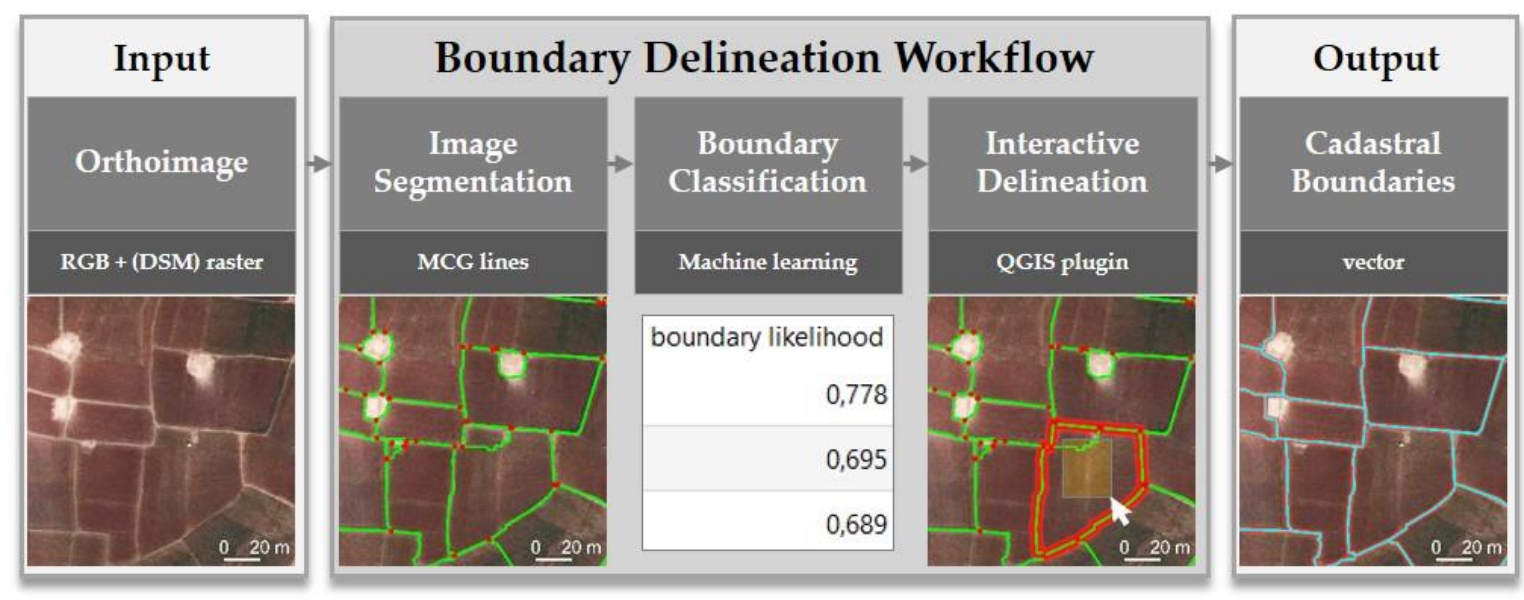

Figure 3: Boundary delineation workflow: (a) Multiresolution combinatorial grouping (MCG) image segmentation. (b) boundary classification (c) interactive delineation guided by a QGIS plugin.

(a) Image segmentation provides closed contours taking the outlines of the visible boundaries in the image. The multiresolution combinatorial grouping method (MCG) was selected for the creation of closed contours based on the UAV data (S. Crommelinck et al., 2019).

(b) Boundary classification requires labeling into "boundary" and "not boundary" to produce training data. Therefore, a set of features are calculated per line, capturing its geometry and 
its spatial context. These features, together with the labels, are used for training an open-source Random Forest (RF) classifier, which predicts boundary likelihoods for the testing data.

(c) Interactive delineation allows users based on the RGB orthophoto to accept the automatically generated boundaries or correct them. The expert can make use of four functionalities that help in speeding up the delineation process. We implemented (c) as a publicly available plugin (Crommelinck.S, n.d.) for the open-source geographic information system QGIS (QGIS Development Team, n.d.).

\subsection{Land information platform for publishing and sharing}

Publish and Share $(\mathrm{PaS})$ is a geocloud platform developed by the German commercial company Hansa Luftbild for hosting and integrating tools and data which facilitates land tenure recording services and applications. Publish and Share provides the framework of common APIs and services used by all its4land tools (Figure 4). The user can select those its4land tools which best fit his/her task.

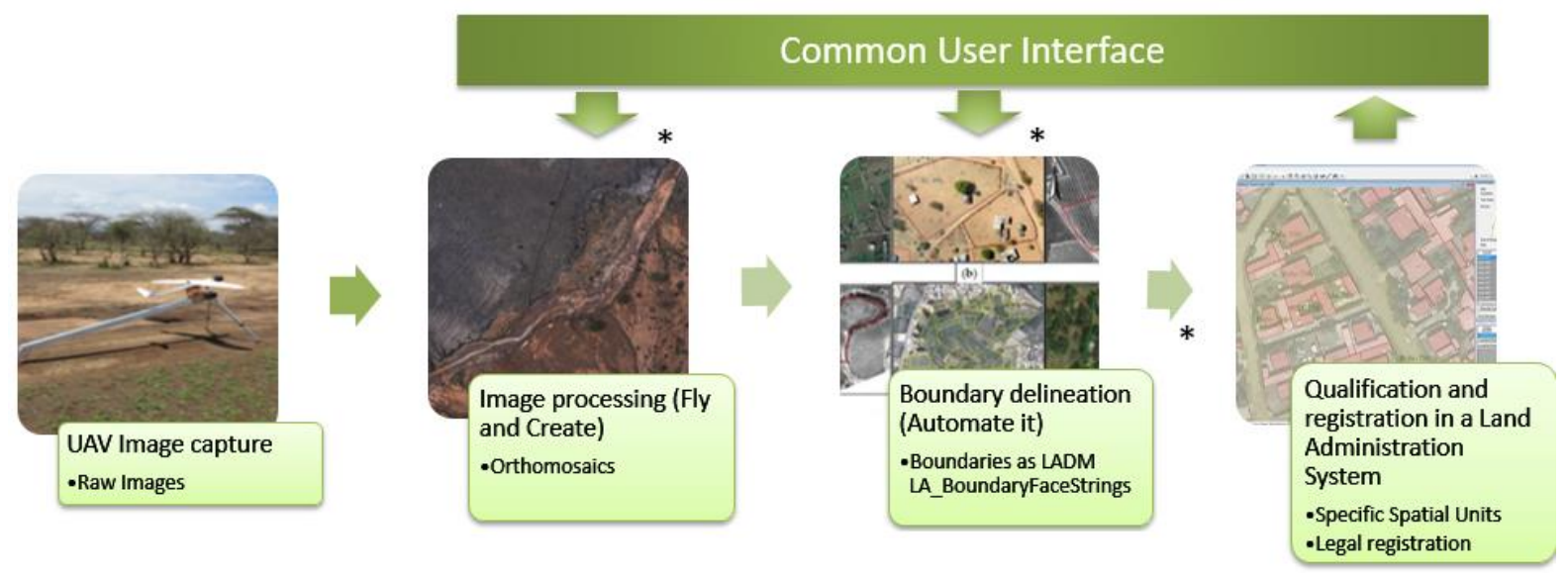

Figure 4: Publish and Share platform, integrating all its4land tools.

The three main concepts of PaSare (1) LADM (ISO 19512: Land Administration Domain Model);

(2) Web based API; (3) Geocloud services platform. LADM provides the conceptual framework (SpatialUnits, AdminSources, etc.) available in the PaS Application Programming Interface (API). However, the meaning of the above mentioned depends on country implementation. The webbased API is independent of programming languages and operating systems. The common data repository helps to reduce the amount of work in a standard land administration setting. Dissemination and sharing of data are based on standards from OGC and W3C. Publish and Share platform is hosted by Amazon Web Services, which is a cloud environment and is open source. Moreover, the LADM concepts were considered when modelling the interfaces of PaS was done. External land administration systems (LAS) can be integrated based on specific national rules. 


\subsection{Consultancy Services for developing governance and capacity models}

The its4land project partner, KU Leuven, undertook the work dealing with the development of the governance and capacity development models. The governance model supports the use of innovative geospatial tools taking into account users' opinions, technological advances, and capacity building necessities. Prior to the model development, an investigation and understanding of the advantages and limitations of the current governance strategies had to be done. Afterwards, suggestions and recommendations in support of governance performances in the context of geospatial innovation implementation in East Africa were done. Its4land consultancy services are offered to NGOs, public or private organizations, which are interested in the application of the its4land software tools $/=$ or PaS platform as a whole.

\section{Result}

\subsection{Results from the needs assessment}

The results from the needs assessment confirmed that cadastral data is recognized as highly critical. The history of land-based conflict indicated that there is a need for regular data updating and storage of the history of each land transaction with the respective rights, restrictions, and responsibilities. Moreover, from the obtained feedback during the workshops, it was concluded that not only data is important but the access, functionality, and type of used tools. Both national and sub-national stakeholders emphasized the necessity for high accurate cadastral data and its integration with the existing land use and. Moreover, data accessibility, stakeholder engagement, and up-to-date web-based master plans were identified as a clear need. In response to these needs, UAVs were found out to be of most potential. SmartSkeMa, Boundary delineator, and geocloud services had less clear innovation pathways. This was mainly due to the problems that users often had in understanding the concepts behind the tools. The experience gained in this project qualifies the its4land project partners to offer consultancy services in the area of needs assessment to organizations (public/private or NGO) for establishing a land administration framework.

\subsection{Results from the integration of the tools in Publish and Share platform (PaS)}

The joint used case aimed to demonstrate how the land administration office can proceed in updating land tenure records for residential and agricultural parcels using the developed its4land tools in the PaS platform. Prior to generating parcel boundaries, UAV images had to be captured to process a high-resolution orthophoto. The UAV flights were carried out by the local Rwandan UAV company Charis UAS Ltd, which holds the required operational license complying with the Rwandan UAV ("RCAA Ministerial Regulations No 01/MOS/Trans/016 of 26/04/2016 Relating to Unmanned Civil Aircraft System; 2016;" "n.d.). The study area, for its4land project, in Musanze covered $3 \mathrm{~km}$ and was selected by Rwanda Land Management and Use Authority to conduct a systematic updating of the cadastre during the financial year 2019-2020 due to the large urban 
developments that occurred during the past years. In collaboration with RLMUA, Charis UAS Ltd., INES Ruhengeri, and Esri Rwanda, more than 8000 high-resolution RGB images were acquired with a DJI Inspire Pro UAV. To obtain the needed resolution of $2 \mathrm{~cm}$., the flying height was set to $120 \mathrm{~m}$., image forward overlap was $80 \%$ and the side overlap was $75 \%$. To cover the study area, 19 individual flights were needed. For georeferencing purposes, 14 ground control points prior to the fight were marked on the terrain and measured with GNSS (Trimble R8). The accuracy of the measurements was below $2 \mathrm{~cm}$ as the GNSS devices were connected to the RTK network of the continuously operating Rwandan reference system (Figure 5). For the joint use case in Rwanda, the overall geometric accuracy of the orthophoto created with the OrthoGenerator was $10.3 \mathrm{~cm}$, with a ground sampling distance of $2.1 \mathrm{~cm}$.

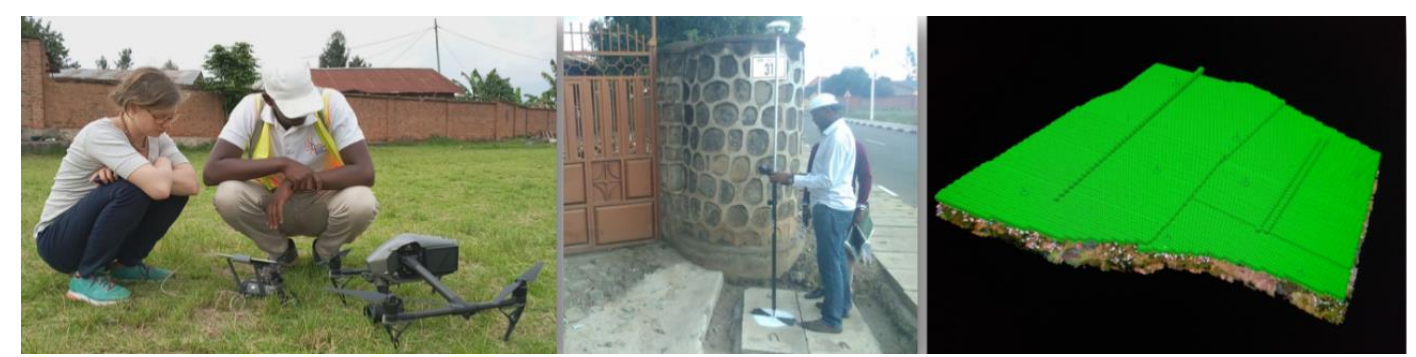

Figure 5: UAV data collection. left: checking the UAV DJI Inspire Pro before the flight; center: measurement of ground control points for georeferencing; right: data processing.

As input information, orthophotos from UAVs were used for the Boundary delineation and SmartSkeMa tools, and also land tenure information from community mapping. For the second case, people draw parcels on top of the orthophotos and indicate the land tenure information (Stöcker, Koeva, \& Zevenbergen, 2020) (Figure 6).
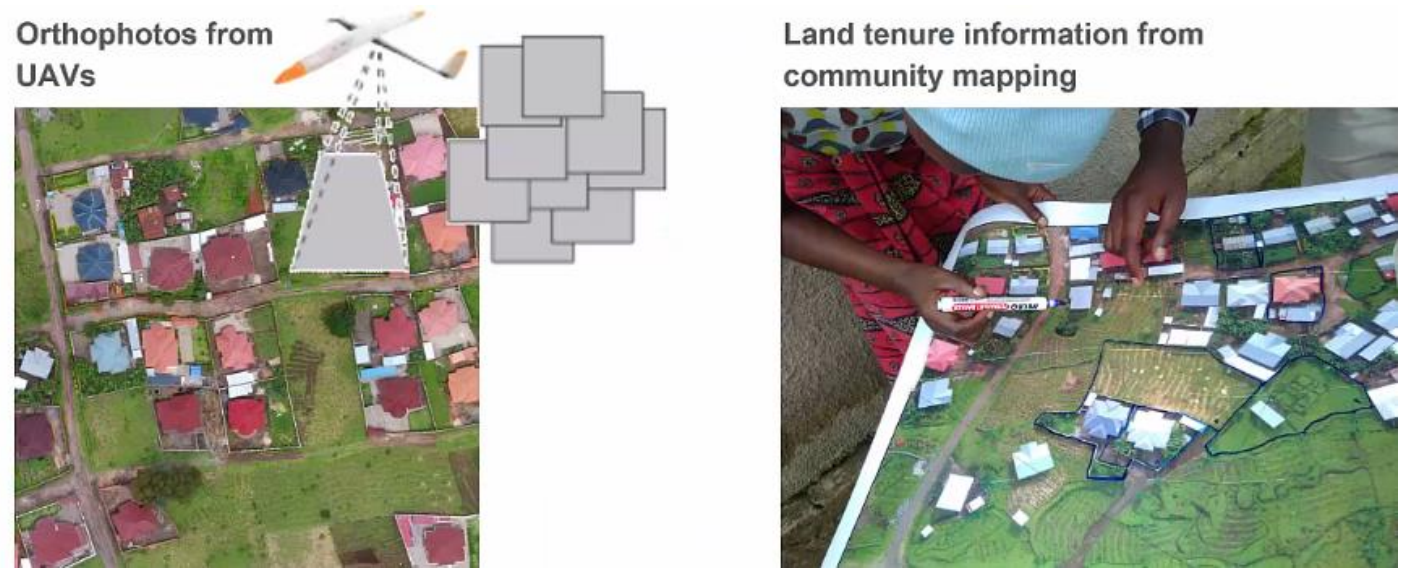

Figure 6: Input data (UAV orthophotos and land tenure information from community mapping).

The three its4land tools (1) OrthoGenerator, (2) Boundary delineator, and (3) SmartSkeMa run via common user interface under the $\mathbf{P a S}^{1}$ as it was shown in Figure 4. 
The UAV orthophoto was used as input for the next tool, which is Boundary Delineator. This tool is an external tool that is using the application development of the Publish and Share platform and combines functionalities implemented in Matlab, Phyton, and QGIS plugin. After opening the QGIS plugin, the orthoimage and the segment layer are loaded (Figure 7).

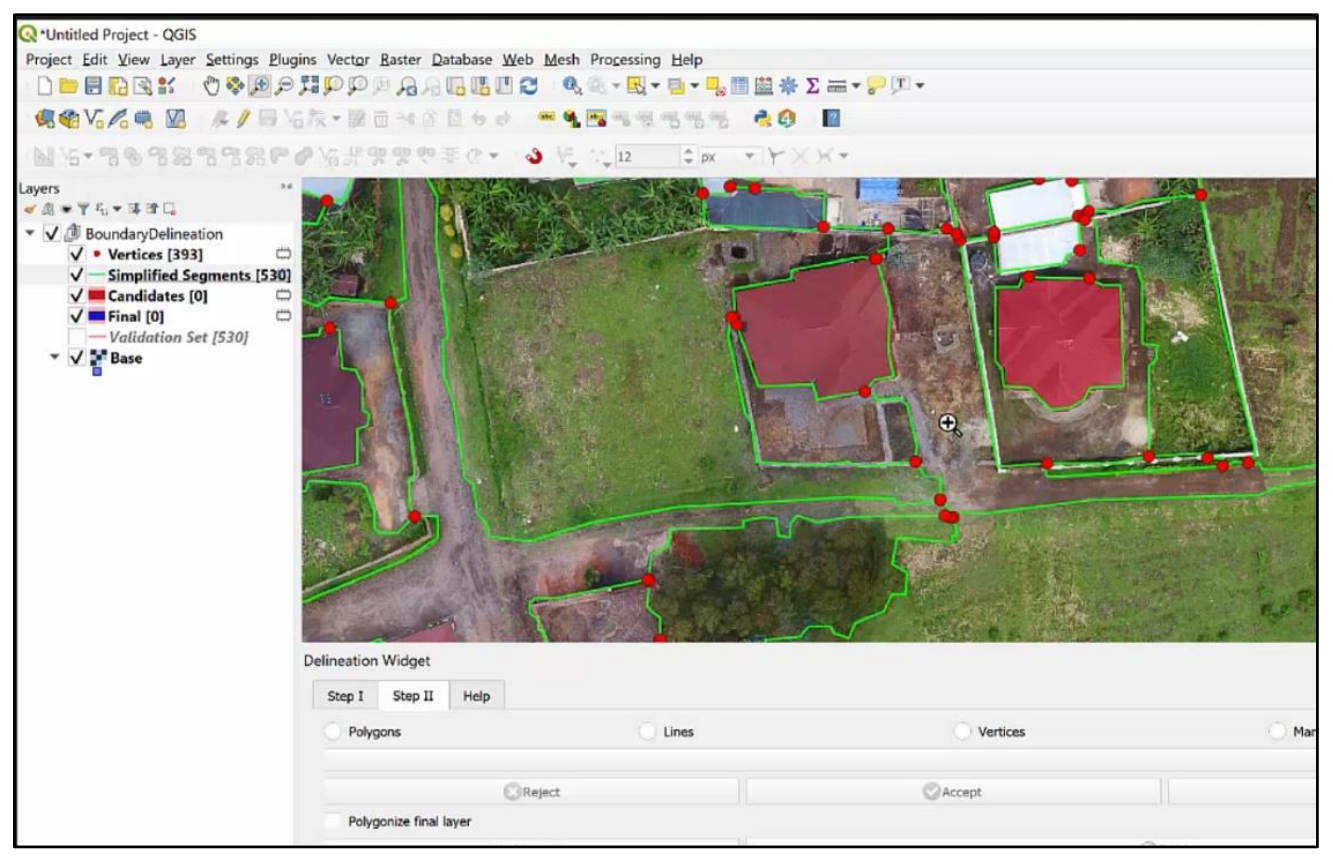

Figure 7: its4land boundary delineation QGIS plugin

After processing the data, the vertices where two green lights meet can be seen. Afterwards, interactive delineation, using the developed functionalities for point, line and polygon editing (StepII), was done. After accepting, the boundaries are automatically stored and can be visualized in PaSplatform. In support of collecting local knowledge, SmartSkeMa was used. Handrawn sketchmaps on top of the orthophoto were be used. To use the sketchmaps in SmartSkeMa, manually added and labeled reference points and polygons from the community mapping had to be drawn on top of a transparent sheet. (Figure 8).

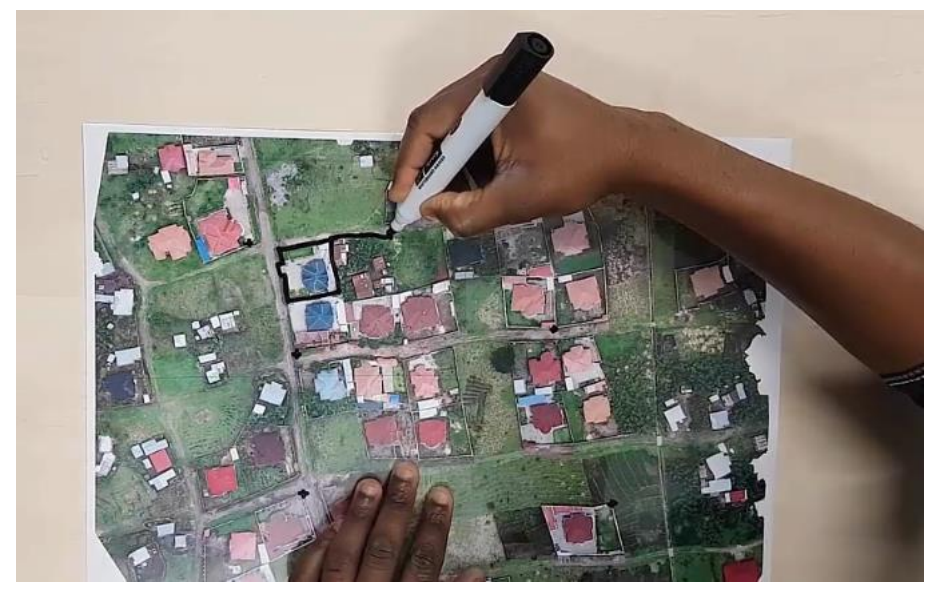

Figure 8: Drawing and labeling reference points and parcel boundaries on top of the transparent sheet over the orthophoto 
The transparent sheet afterward was removed and scanned in order to be used as input for the SmartSkeMa. The land tenure information was noted down for each parcel. SmartSkeMa was started in a separate browser where the input data (the sketch and the orthophoto) from the PaS platform is loaded. The tool extracted the boundary contours of drawn geographic features and allowed to align the features to a georeferenced base map (Figure 9).

Afterwards, the process of automatic vectorization started. Then all the polygons from the image are detected, and when clicking on "align to geometry" the two visualizations are linked based on the reference points. After that, the land tenure information was digitally annotated for each polygon with its rights, restrictions, and responsibilities (RRR) (Figure 9).
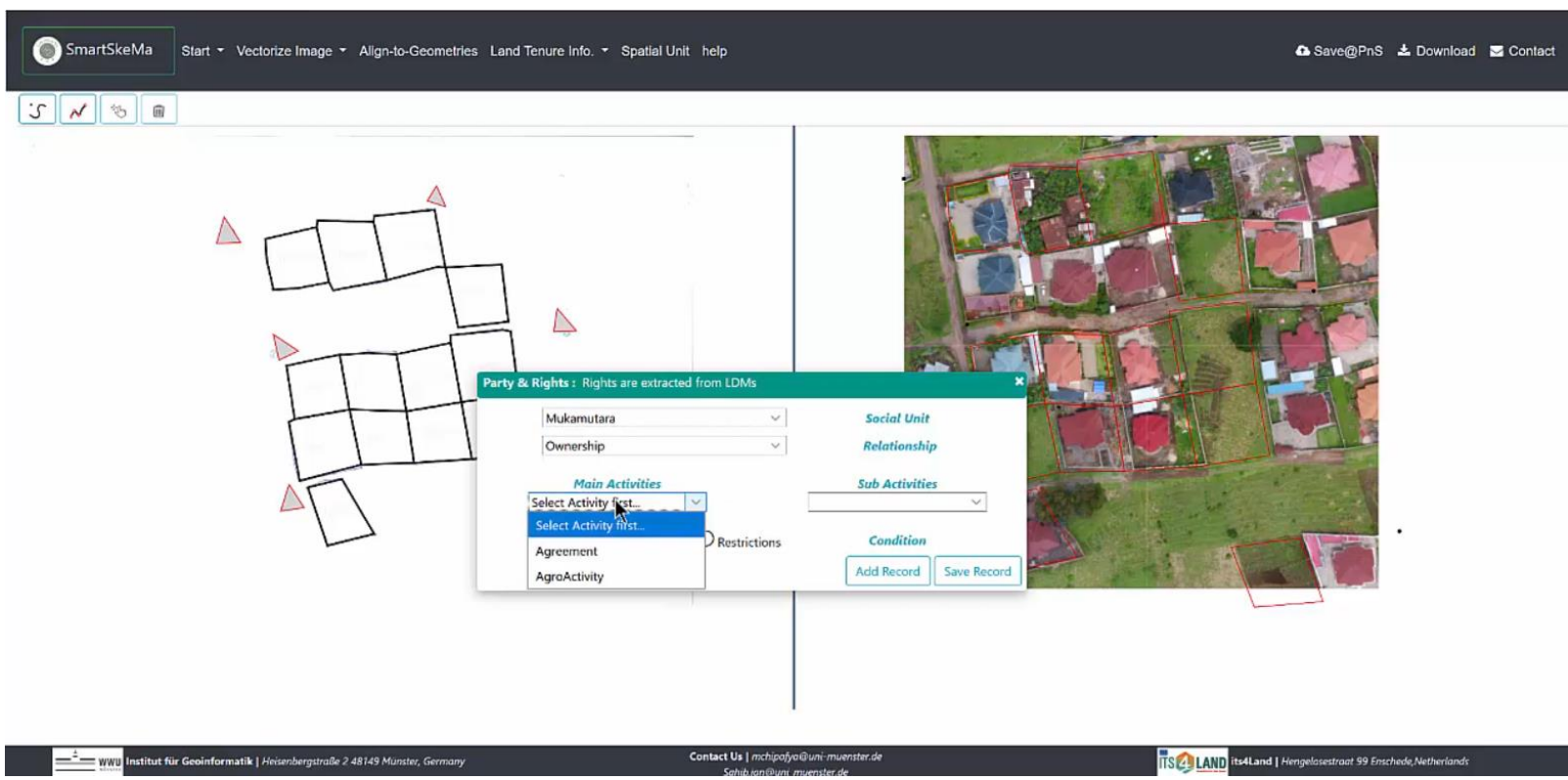

Figure 9: Georeferences sketch map aligned with the orthophoto in SmartSkeMa.

After saving the results from SmartSkeMa, the output of all three tools is visualized and overlayed in the PaS platform, as seen in Figure 10 below. The output of the boundary delineator is in dark blue color, and the output from SmartSkeMa is in a yellow polygon.
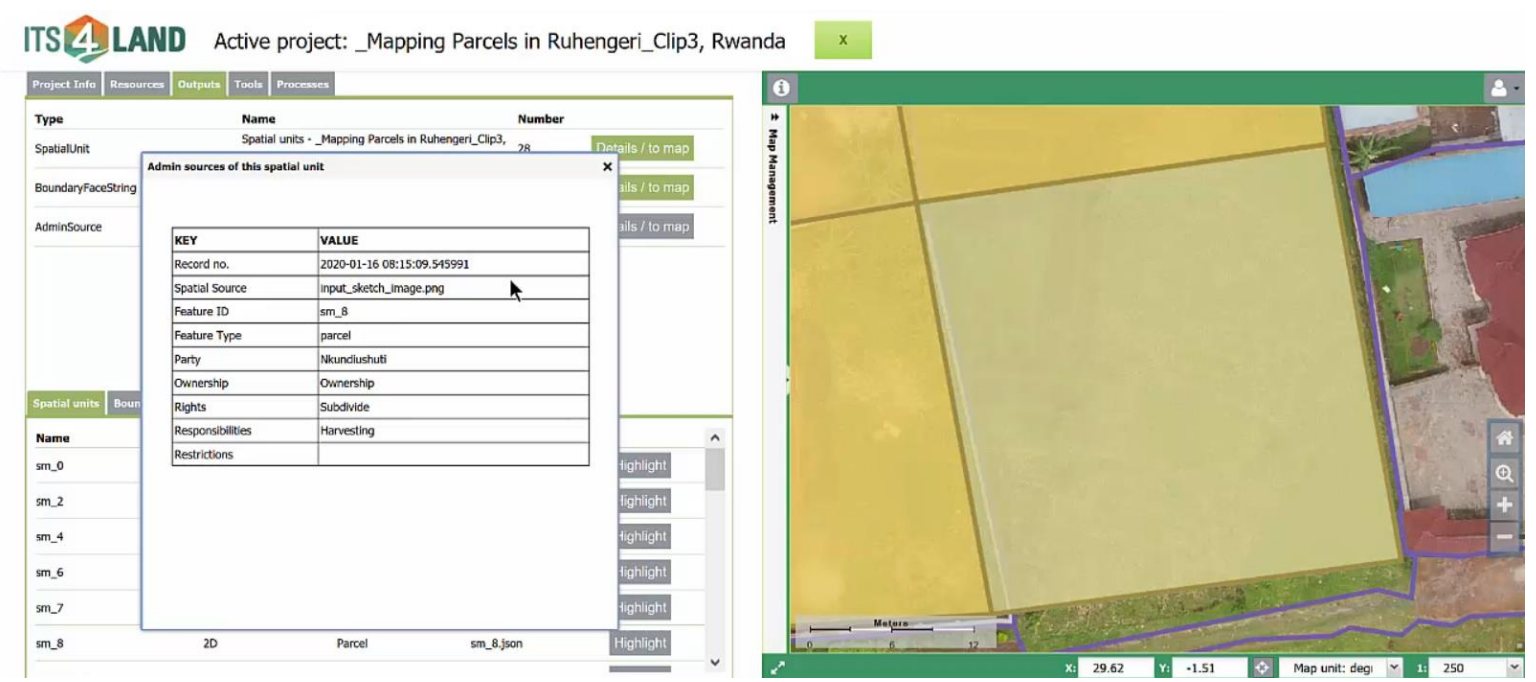

Figure 10: Outputs of all the three tools overlayed in the PaS platform. 
Since the geometries of SmartSkeMa are coming from community mapping, they are less precise than the one from the Boundary delineator. However, they include potentially non-visible information, which is only available for the local people.

\subsection{Results from the developed governance and capacity model}

The its4land model is designed to satisfy the needs for the implementation of the geospatial tools in the land administration, and it shows the present challenges in the capacity and governance conditions (e.g., Fit-for-purpose Governance Assessment Framework (FGAF) (Casiano Flores, C., Tan, E., Buntinx, I., Crompvoets, J., Stöcker, C., \& Zevenbergen, 2020). However, the its4land model is also oriented toward realizations in the future, i.e., improving the performance of the LAS to implement the its4land tools. Figure 11 illustrates the visual representation of this systemic view.
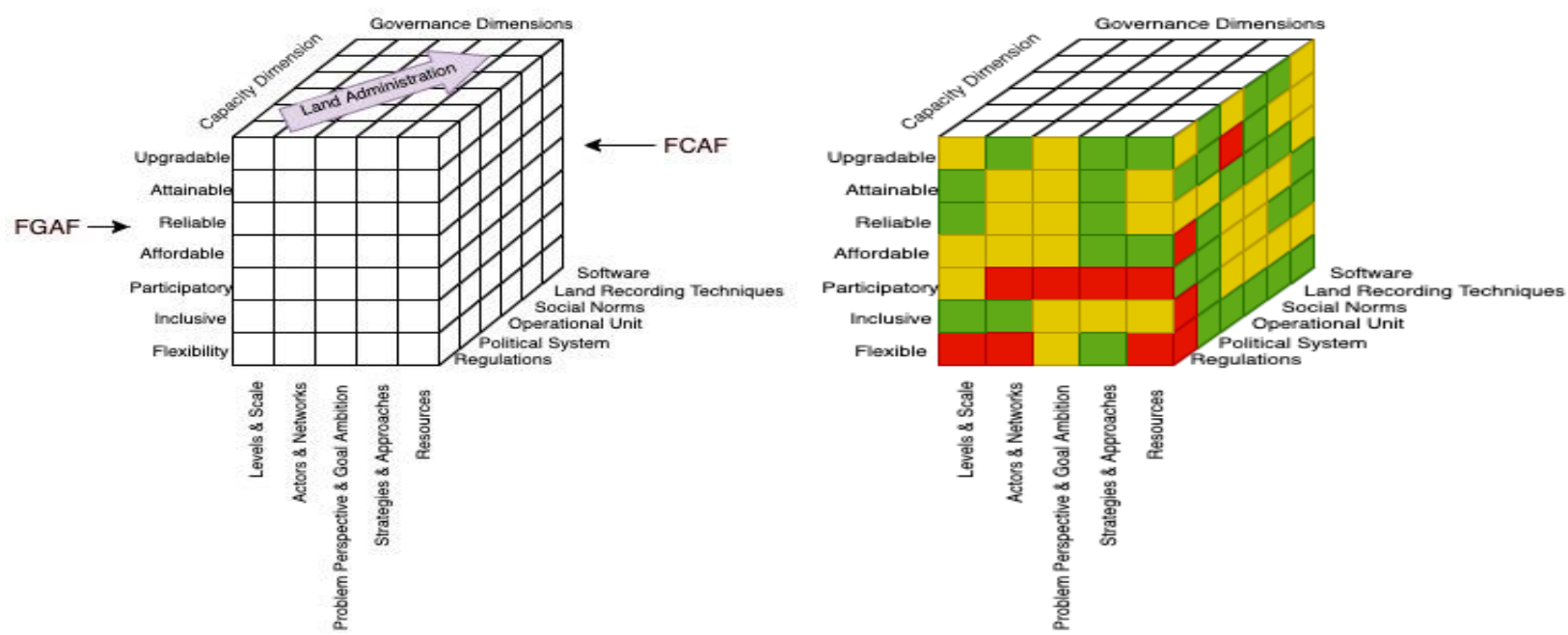

Figure 11: Its4land model for governance and capacity development (left) and the UAV case for Rwanda (right)

The sides of the cube reflect the governance and capacity assessment frameworks. The upper side of the cube represents the systemic dimension of the LAS, which is dependent on the changes in the capacity and governance dimensions. The performance of the LAS is dependent on its ability to utilize the capacity and governance elements to lead into the desired results (e.g., a sustainable adaptation of the its4land tools) in land administration. For Rwanda Figure 11 (right), the models were developed based on feedback obtained from 38 semi-structured interviews in Rwanda (23 referred to the government, 9 to the private sector, 9 to non-governmental organizations, and 5 to the academic sector).

\section{Discussion and conclusions}

The joint case study demonstrated a procedure that can be reproduced in any land administration office for updating land tenure records for residential and agricultural parcels using the developed its4land tools in the PaS platform. Using SmartSkeMa digitization of hand-drawn sketches 
obtained from participatory mapping, the process of land tenure recording can be very fast. Furthermore, it allows delineating invisible from the image boundaries and to associate RRR via the local domain model. However, this method is not so precise as the Boundary delineator, which is using the pixel information from very high-resolution imagery. Therefore, being integrated in PaS using these complementary tools can be beneficial for local administration offices to speed up the mapping an updating cadastre processes.

The multi-level governance of the LAS is mostly compatible with the implementation of the its4land tools. Yet, the governance context in Rwanda favors a top-down and hierarchical approach for the implementation of the its4land technologies. Therefore, the central government plays a key role to incentivize participatory governance models for local, private, and non- governmental actors (Casiano Flores, et al., 2020). The national government and the district land bureaus can operate UAVs and are open to using Boundary delineator and SmartSkeMa, but the sector and cell levels of administration mostly lack the resources to maintain the operations. Regarding PaS, there are significant challenges for its adoption. There is hardly any local support for open source technologies, and the GIS skills, particularly at local government levels, tend to below. Also, the operational units at lower levels of government require appropriate ICT infrastructure and Internet connectivity to access cloud services. However, previous positive FFP approach experiences in Rwanda show their innovation capacity. Considering that the Rwandan government is very eager to innovate and to promote a digital transition, the its4land technology implementation seems feasible in short to a medium time frame.

\section{Acknowledgments}

The research in this paper was funded by the research project "its4land". The project is part of the Horizon 2020 program of the European Union, project number 687828.

\section{References}

Casiano Flores, C., Tan, E., Buntinx, I., Crompvoets, J., Stöcker, C., \& Zevenbergen, J. (2020). Governance Assessment of the UAVs implementation in Rwanda under the Fit-for-purpose Land Administration approach. Land Pse Policy. https://doi.org/10.1016/j. landusepol.2020.104725

Chipofya, M., Jan, S., Schultz, C., \& Schwering, A. (2017). Towards Smart Sketch Maps for Community-driven Land Tenure Recording Activities. In AGILE. Wageningen. Retrieved from https://agile-

online.org/conference_paper/cds/agile_2017/shortpapers/155_ShortPaper_in_PDF.pdf

Crommelinck.S. (n.d.). Delineation-tool GitHub. Retrieved May 13, 2019, from https://github.com/its4land/delineation-tool 
Crommelinck, S., Bennett, R., Gerke, M., Yang, M., \& Vosselman, G. (2017). Contour detection for UAV-based cadastral mapping. Remote Sensing. Retrieved from https://www.mdpi.com/2072-4292/9/2/171

Crommelinck, S. C., Bennett, R. M., Gerke, M., Koeva, M. N., Yang, M. Y., \& Vosselman, G. (2017). SLIC superpixels for object delineation UAV data. In C. Stachniss, W. Förstner, \& J. Schneider (Eds.), Proceedings of International Conference on Unmanned Aerial Vehicles in Geomatics, 4-7 September 2017, Bonn, Germany. Peer-reviewed Annals, Volume IV-2/W3, 201 (Vol. IV-2/W3, pp. 9-16). International Society for Photogrammetry and Remote Sensing (ISPRS). https://doi.org/10.5194/isprs-annals-IV-2-W3-9-2017

Crommelinck, S., Höfle, B., Koeva, M. N., Yang, M. Y., \& Vosselman, G. (2018). Interactive cadastral boundary delineation from UAV images. ISPRS Annals of the Photogrammetry, Remote Sensing and Spatial Information Sciences, 4(2), 81-88. https://doi.org/10.5194/isprsannals-IV-2-81-2018

Crommelinck, S., Koeva, M., Yang, M., \& Vosselman, G. (2019). Application of Deep Learning for Delineation of Visible Cadastral Boundaries from Remote Sensing Imagery. Remote Sensing , 11,1-22. Retrieved from https:/www.mdpi.com/2072-4292/11/21/2505

Delbecq, A. L., \& Van de Ven, A. H. (1971). A group process model for problem identification and program planning. The Journal of Applied Behavioral Science, 7(4), 466-492. https://doi.org/10.1177/002188637100700404

Enemark, S., McLaren, R., Lemmen, C., Antonio, D., \& Gitau, J. (2016). Guiding principles for building fit-for-purpose land administration systems in developing countries. Scaling up Responsible Land Governance. Nairobi, Kenya: UN-Habitat.

Gallagher, M., Hares, T., Spencer, J., Bradshaw, C., \& Webb, I. (1993). The nominal group technique: a research tool for general practice? Academic.Oup.Com. Retrieved from https://academic.oup.com/fampra/artic le-abstract/10/1/76/577561

Ho, S., Pattyn, V., Broucker, B., \& Crompvoets, J. (2018). Needs Assessment in Land Administration: The Potential of the Nominal Group Technique. Land. Retrieved from https://www.mdpi.com/2073-445X/7/3/87

IAAO. (2015). Standard on digital cadastral maps and parcel identifiers. Int. Association of Assessing Officers (IAAO), Kansas City, MO, USA.

Karamesouti, M., Schultz, C., Chipofya, M., Jan, S., Murcia Galeano, C. E., Schwering, A., \& Timm, C. (2018). The Maasai of Southern Kenya Domain Model of Land Use. ISPRS Annals 
of Photogrammetry, Remote Sensing and Spatial Information Sciences, IV-4(4), 105-112. https://doi.org/10.5194/isprs-annals-IV-4-105-2018

Koeva, M., Muneza, M., Gevaert, C., Gerke, M., \& Nex, F. (2018). Using UAVs for map creation and updating. A case study in Rwanda. Survey Review, 50(361). https://doi.org/10.1080/00396265.2016.1268756

Koeva, M. N., Bennett, R. M., Gerke, M., Crommelinck, S. C., Stöcker, E. C., Crompvoets, J., ... Kundert, K. (2017). Towards innovative geospatial tools for fit-for-purpose land rights mapping. (D. Li, Ed.), Proceedings ISPRS Geospatial Week 2017, 18-22 September 2017, Wuhan, China. Wuhan: International Society for Photogrammetry and Remote Sensing (ISPRS). https://doi.org/https://doi.org/10.5194/isprs-archives-XLII-2-W7-37-2017

Koeva, M. N., Crommelinck, S., Stöcker, C., \& Crompvoets, J. (2018). Its4land - Challenges and Opportunities in Developing Innovative Geospatial Tools for Fit-For-Purpose Land Rights Mapping. In FIG Congress 2018 (pp. 1-17). Copenhagen: International Federation of $\begin{array}{llll}\text { Surveyors } & \text { (FIG). } & \text { Retrieved }\end{array}$ https://ezproxy2. utwente.n1/login?url=https ://webapps. itc.utwente.nl/library/2018/chap/koev a_its.pdf

Koeva, Mila, Stöcker, C., Crommelinck, S., Ho, S., Chipofya, M., Sahib, J., ... Pattyn, V. (2020). Innovative remote sensing methodologies for Kenyan land tenure mapping. Remote Sensing, 12(2), 1-27. https://doi. org/10.3390/rs12020273

QGIS Development Team. (n.d.). QGIS Geographic Information System, Open Source Geospatial Foundation. Retrieved December 16, 2019, from https://www.qgis.org/en/site/

RCAA Ministerial Regulations No 01/MOS/Trans/016 of 26/04/2016 Relating to Unmanned Civil Aircraft System; 2016; (n.d.). Retrieved June 4, 2020, from https://www.google.com/search?clie nt=firefox-b$\mathrm{d} \& \mathrm{q}=\mathrm{RCAA}+$ Ministerial+Regulations+No+01\%2FMOS\%2FTrans $\% 2 \mathrm{~F} 016+\mathrm{of}+26 \% 2 \mathrm{~F} 04$ $\%$ 2F2016+Relating+to+Unmanned+Civil+Aircraft+System\%3B+2016\%3B

Schwering, A., Wang, J., Chipofya, M., Jan, S., Li, R., \& Broelemann, K. (2014). SketchMapia: Qualitative Representations for the Alignment of Sketch and Metric Maps. Spatial Cognition \& Computation, 14(3), 220-254. https://doi.org/10.1080/13875868.2014.917378

Stöcker, C., Koeva, M. N., \& Zevenbergen, J. A. (2020). UAV Technology: Opportunities to support the updating process of the Rwandan cadastre. In FIG Working Week 2020. Amsterdam. Retrieved from https://www.fig.net/resources/proceedings/fig_proceedings/fig2020/papers/ts07h/TS07H_st 
ocker_koeva_et_al_10290.pdf

Thierry Ngoga. (2017). Land Governance Assessment Framework - Rwanda. March.

Xia, X., Koeva, M., \& Persello, C. (2019). Extracting Cadastral Boundaries from UAV Images Using Fully Convolutional Networks. In IGARSS 2019 - 2019 IEEE International Geoscience and Remote Sensing Symposium (pp. 2455-2458). IEEE. https://doi.org/10.1109/IGARSS.2019.8898156

Xia, X., Persello, C., \& Koeva, M. (2019). Deep Fully Convolutional Networks for Cadastral Boundary Detection from UAV Images. Remote Sensing, 11(14), 1725. https://doi.org/10.3390/rs1 1141725 